\title{
CEREBRAL CYSTICERCOSIS COMPLICATED BY PYOGENIC MENINGITIS
}

\author{
By A. C. Chappell, M.B., Ch.B. \\ Merthyr Tydfil General Hospital
}

This communication records a case of cerebral cysticercosis, symptoms having been present over I 7 years, and death caused by the unusual and unrelated complication of pyogenic meningitis secondary to middle ear infection.

The patient, a single man of British nationality aged 54 years, was admitted as an emergency to Merthyr Tydfil General Hospital on 22.10.57, as a case of cerebral cysticercosis, under the care of Dr. J. M. Swithinbank.

He had been an in-patient in Cardiff Royal Infirmary under Dr. J. D. Spillane from 8.I I.50 to 22.1 I.50, when he gave a Io-year history of attacks of epilepsy, commencing in the left thumb and left angle of the mouth, spreading, sometimes violently, to involve the whole of the left side. The attacks occurred in bursts, lasting about a week, and were separated from one another by periods of several weeks or months. He only became unconscious on one occasion and there were no post-epileptic phenomena. There was no family history of epilepsy. He had served in the Army in India from 1926-3I.

\section{On Examination (8/11/50)}

Patient of low I.Q. with a marked stammer and evidence of early dementia. Memory for recent events poor and powers of concentration indifferent.

General condition fair. The blood pressure was 120/60. No abnormality was detected in the cardiovascular, respiratory or central nervous systems.

There were subcutaneous nodules palpable over his skin, which were non-tender and mobile.

\section{Investigations}

(I) A muscle biopsy (right biceps) under local anaesthetic microscopical examining showing a cysticercus. (2) X-rays of skeleton demonstrated hundreds of calcified cysticerci, especially in the thigh muscles. X-rays of skull showed opacities at the clivus and in the floor of the posterior fossa, possibly calcified cysticerci, but on the evidence of the films available not definitely intracranial.
(3) The E.E.G. was within normal limits. (4) Lumbar puncture: Pressure normal; cells 24 per cu. m.m. (mononuclears); protein $5 \mathrm{I} \mathrm{mg.} \mathrm{per} \mathrm{cent.;}$ Lange normal and W.R. negative. (5) Blood o picture: HB. 14.0 g. $/ 100 \mathrm{ml}$. (97 per cent.); W.B.C. I 4,800 per cu. m.m. Differential: 7 per cent. eosinophils ( 1,036 per cu. m.m.). (6) Air en- $\vec{G}$ cephalogram: 60 c.c. air introduced by the lumbar route. No filling of ventricles obtained. Cerebral $\stackrel{\circ}{工}$ sulci appear larger than normal. Probably one or two cysticerci seen inside the skull.

\section{Treatment}

Epanutin, gr. $1 \frac{1}{2}$ t.d.s., and phenobarbitone gr. $\frac{1}{2}$ t.d.s.

In August 1955 the patient, by then utre employed, was referred to Medical Out-patients at Merthyr General Hospital. There was little change in symptoms or in his general condition. Further X-rays were taken:

Skull: ' Some calcified cysticerci present on the left side-one in the occipital region and one behind the sella in the lateral view. These are probably in the scalp and surrounding muscles, however. There are several to be seen in the facial region also. There is considerable sclerosis of the right mastoid.'

Thighs: 'Large numbers of calcified cysticerci are present in the muscles.'

On his last admission (22.10.57) it was impossible to obtain a detailed or accurate history, 욱 since the patient was stone deaf and his vision $D$ impaired to a degree which made him able to read only large printed letters.

It appeared that his fits had been infrequent during the past two years, but he gave a three-day history of frontal and occipital headachesgradually becoming very severe-slight fever, loss of appetite and sore throat. His deafness had progressed over the previous few months.

\section{Examination (22/10/57)}

This revealed a fully conscious patient, probably of low intelligence. He was well orientated, but 


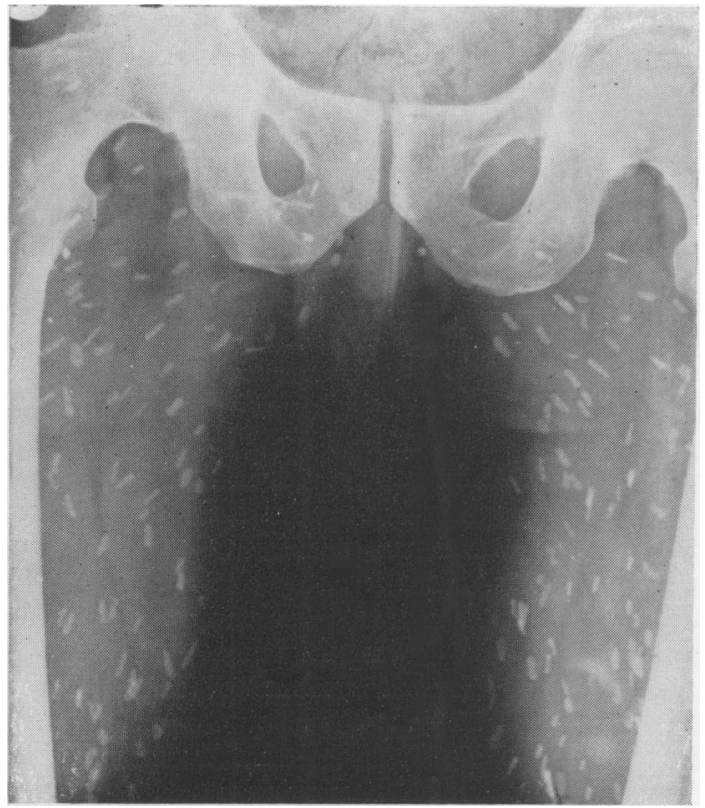

Radiograph of thighs (1955) showing numerous calcified cysticerci in the muscles.

powers of concentration and memory were poor and there was a marked stammer. Average physique. Temperature $98^{\circ} \mathrm{F}$. No clinical evidence of anaemia or lymphatic enlargement.

\section{Skin}

Two calcified superficial cysticerci nodules were palpable, one in the left sternomastoid and the other over the left costal margin.

\section{C.V.S.}

Pulse normal. B.P. r6o/9o. Heart N.A.D.

R.S.

Few crepitations audible at both lung bases, otherwise N.A.D.

\section{S.}

Herpes of lower lip. Tonsils and pharynx appeared inflamed.

Abdomen: Appendicectomy scar in R.I.F. Liver, spleen, kidneys impalpable.

\section{Ears}

There was no tenderness over the mastoid processes. The left external auditory meatus and car drum appeared normal. There was slight serous discharge in the right E.A.M. and the drum was destroyed and obscured by a fringe of granulations. Aerially conducted sounds (medium tuning fork) were not audible, but slight vibration was detected on both sides to the bone conduction test.

\section{C.N.S.}

There was marked neck stiffness, and tenderness in the occipital region. Kernig's and Brudzinski's signs were negative. Pupils equal and normal in size, reacting to light and accommodation. Optic fundi: normal. Cranial nerves: N.A.D. Muscle tone and power normal; no evidence of paralysis. No impairment of touch, pain, position and vibration sense. Reflexes brisk and symmetrical. Plantar responses-flexor.

\section{Investigations}

(I) Lumbar puncture: Turbid fluid under slightly increased pressure. Protein $525 \mathrm{mg}$. per cent.; sugar $12 \mathrm{mg}$. per cent.; cells 6,400 W.B.C. per cu. m.m., mainly polymorphs. Direct smear: Pus cells and scanty gram-ve bacilli. Culture: No growth after 48 hours. (2) Blood picture: HB. 97 per cent. (I 4.4 g.); W.B.C. I4,600 per cu. m.m. (polymorphs $8 \mathrm{r}$ per cent., lymphocytes 12 per cent., monocytes, 7 per cent.). (3) Urine (midstream specimen): Trace of albumin. Scanty hyaline and granular casts. Few pus cells and 20-30 red cells per h.p.f. (4) Throat swab: Growth of Staph. aureus (coag.+ve) (sensitive to penicillin, streptomycin, aureomycin, terramycin, chloramphenicol, erythromycin, tetracycline, novobiocin) and monilia albicans. (5) Swab from right ear: Profuse growth of $B$. pyocyaneus and Staph. aureus (coag. + ve) and $\beta$ haemolytic streptococci. Combined sensitivity: Insensitive to all the above-mentioned antibiotics.

\section{Treatment}

In view of the poor general state of the patient and turbid appearance of the C.S.F. it was thought advisable to commence antibiotic treatment immediately. 20,000 units of benzyl penicillin were administered intrathecally and oral chloramphenicol commenced in a dosage of $500 \mathrm{mg}$. six-hourly. Headache was partly alleviated by intramuscular injections of $100 \mathrm{mg}$. pethidine.

\section{Progress}

During the first 24 hours the patient's condition remained unchanged, but following this there was a deterioration. Temperature rose to 101. ${ }^{\circ} \mathrm{F}$., he became restless, confused and semicomatose. Neck retraction appeared and Kernig's sign became positive, while the plantar responses were extensor. There was no papilloedema, nor any other abnormal finding in the C.N.S. There were numerous coarse rales at right lung base. The addition of crystalline penicillin $(500,000$ units six-hourly) and streptomycin (I g. b.d.) to 
the chemotherapy and measures to reduce cerebral oedema (repeated injections of 50 c.c. 50 per cent. sucrose intravenously and 12 c.c. 25 per cent. magnesium sulphate intramuscularly) were without effect and the patient died on 24.10.57, 48 hours after admission.

\section{Post-mortem Examination (25.10.57)}

External findings

Circulatory system

Gastro-intestinal tract

Haemopoietic system

Organs of internal secretion

Genito-urinary system

\section{Respiratory System}

Frothy yellow mucoid material in trachea and bronchi. Both lungs considerably oedematous and congested. Broncho-pneumonia of right lower lobe.

\section{Muscles}

Small calcified nodules 3 to $5 \mathrm{~m} . \mathrm{m}$. in diameter were present in the left pectineus major and the extensor muscles of the left thigh (other muscle masses not examined).

\section{Nervous System}

There was a basal meningitis maximal over the inferior surface of the right temporal lobe, opposite the infected mastoid. No cysticerci were present in the meninges, but many were found as small cysts 3 to $5 \mathrm{~m} . \mathrm{m}$. in diameter scattered throughout the cerebral hemispheres, which were otherwise normal. The ventricles were normal and not dilated and contained C.S.F. under slightly increased tension. There was no evidence of blockage to the circulation of the C.S.F. No signs of gross cerebral oedema and no tentorial pressure cone.

\section{Histology of Cysticercoid Lesions}

Thick-walled cysts of dense fibrous tissue infiltrated with plasma cells and lymphocytes. Parasitic elements represented in some sections as convoluted hyaline structures.

\section{Discussion}

During the last decade or two increasing attention has been paid to the condition of cerebral cysticercosis and since MacArthur's (1934) work on the epileptic mode of presentation, series of cases have been collected, especially from Latin America and Eastern Europe, which illustrate the protean manifestations of this interesting disease.

This patient almost certainly contracted his infection with ova of Taenia solium while in India (1926-3I), although no further details of this period are available. In their series of 284 cases amo service personnel and families Dixon and Smithers (1944) were able to show that 274 of these u⿳亠े⿵冂卄 doubtedly became infested while in India. The incubation period is given as a few months to years and in this case was probably about ro yeas.

The long history of repeated attacks of fowl epilepsy and one or two more generalized coㅌvulsions, together with mental and possibly visuli deterioration, are the main features up until is last illness. Other diagnostic points incluge appearance of calcified cysticerci in radiographs of the skeleton, raised blood eosinophil count and raised protein and lymphocytes in the C.S.F.

The provisional diagnosis on his admission 22.10.57 was an aseptic meningitis provoked \&y the liberation of toxin from cyst or cysts situated near, or rupturing into, the meninges. T occurrence of attacks of meningitis and/or meningoencephalitis in cases of cerebral cysticercosis ha6 been described, among others, by Obrador (1 948 , Bickerstaff (1955) and Arseni and Samitca (I95\%). Pyogenic suppuration is very rare and the lattor describe it as being due to delayed secondary infection or transportation of bacteria with the cysts. No account can, however, be found of amy case with the unrelated complication of a pyogenic meningitis.

The evidence for this diagnosis rests on the presence of a source of infection, results of lakầrg tory investigations and the post-mortem finding

There were clinical signs of infection in the throat and chest, as well as chronic infection in the right ear. Pathogenic organisms were cultured from discharge obtained from the latter; and radiographic abnormality seen in 1955 .

The finding of a purulent C.S.F. with as much as $525 \mathrm{mg}$. per cent. of protein and 6,400 cells per cu. $\mathrm{mm}$. is strongly in favour of the diagnosis. The usual abnormal C.S.F. findings in a case of cerebral cysticercosis comprise raised prote (usually < $100 \mathrm{mg}$. per cent.), pleocytosis of 15 th roo cells (mainly lymphocytes) and normal or slightly reduced sugar.

Obrador (1948) also states that a C.S.F. glucoge of below $50 \mathrm{mg}$. per cent. is a frequent and important sign and that cysticercosis is the on chronic disease of the nervous system causing suath low values. It is, nevertheless, felt that in this case the low sugar is indicative of a bacterial if fection. During attacks of meningo-encephalis the C.S.F., and sometimes the blood, may showga marked eosinophilic reaction in cases of cystcercosis, presumably an expression of allergy. this case, however, no eosinophils were seen of routine differential white blood count, white Gram and Leishmann stains of C.S.F. showed the polymorphs to be of the neutrophil variety. The 
failure to cultivate any organisms from the single specimen of C.S.F. obtained may have been due to the delay of an hour or two between lumbar puncture and incubation on the culture media (aerobic blood agar plate, and dextrose broth). He had not received antibiotic treatment prior to hospital admission. Finally, from the post-mortem findings the absence of any intense cerebral oedema, internal hydrocephalus and pressure cone which could be attributed to cysticercosis, and the presence of a meningitis maximal over the infected mastoid process, suggests that spread of infection from the latter caused the meningitis. This, together with a broncho-pneumonia, is considered to be the immediate cause of death.

\section{Acknowledgments}

My thanks are due to Dr. J. M. Swithinbank and Dr. J. D. Spillane for permission to publish this case, Dr. J. P. Dearnaley for carrying out the post-mortem and to Dr. E. R. Bickerstaff and Dr. Swithinbank for helpful criticism.

\section{BIBLIOGRAPHY}

MACARTHUR, W. P. (1934), f. roy. Army med. Cps., 62, $24 \mathrm{I}$. DIXON and SMITIYIERS (1944), Quart. F. Med., 13, 107. OBRADOR, S. (1948), Arch. Neurol. Psychiat. (Chicago), 59, 457.

BICKERSTAFF, E. R. (1955), Brit. med. f., 4921, 1055. ARSENI and SAMJ. I'CA (1957), Brit. med. $\mathcal{F} ., 5043,491$.

\section{HEPATIC DISEASE}

(Postgraduate Medical Journal)

Price: 4s. 0d. post free

\author{
JAUNDICE \\ Sheila Sherlock, M.D., M.P.C.P. \\ HEPATIC COMA \\ J. M. Walshe, M.A., M.R.C P. \\ SURGICAL TREATMENT OF PORTAL \\ HYPERTENSION \\ A. I. S. Macpherson, Ch.M., F.R.C.S.E.
}

WILSON'S DISEASE

A. G. Bearn, M. D.

\author{
ASCITES IN LIVER DISEASE \\ Michael Atkinson, M.D. (Lond.) \\ M.R.C.P. \\ PSYCHIATRIC ASPECTS OF LIVER \\ DISEASE \\ Esther A. Davidson, M.R.C.P.Ed., and \\ W. H. J. Summerskill, M.A., M.R.C.P. \\ PERCUTANEOUS PORTAL \\ VENOGRAPHY \\ David Sutton, M.D., M.R.C.P., F.F.R.
}

Published by

THE FELLOWSHIP OF POSTGRADUATE MEDICINE

60, Portland Place, London, W.1 